\title{
Development of Technical and Technological Solutions in the Field of Multilayer Graphene for Creating Electrode Nanomaterial Energy Storage Devices
}

\author{
N.R. Memetov, A.V. Schegolkov, G.V. Solomakho and A.G. Tkachev
}

\begin{abstract}
The technologies of production of graphene nanoplatelets and nanocomposite materials (nano-, meso-porous carbon)/(graphene nanoplatelets, carbon nanotubes) were developed. The nanocomposite materials obtained possess specific surface area as high as $2000-3000 \mathrm{~m}^{2} / \mathrm{g}$ and more, and exceed the existing carbon materials by parameters of surface area, pore volume, and pore size. Supercapacitors based on the nanocomposite materials developed were made and tested.
\end{abstract}

Keywords Graphene nanoplatelets · Carbon-carbon composites Electrode materials $\cdot$ Supercapacitors

\section{Introduction}

Power engineering and energy technologies in the past years came to the forefront of technical and social progress. The efficiency of technologies of energy conversion, transfer, and storage become more and more important.

Modern energy-intensive electrical and electronic systems put forward strict requirements to the power supplies. A variety of equipment-from digital cameras

\footnotetext{
N.R. Memetov · A.V. Schegolkov · G.V. Solomakho · A.G. Tkachev ( $)$

Federal State Budgetary Educational Institution of Higher Professional Education, Tambov

State Technical University, Tambov, Russia

e-mail: nanotam@yandex.ru

N.R. Memetov

e-mail:mnr979@gmail.com
}
A.V. Schegolkov
e-mail: energynano@ya.ru
G.V. Solomakho
e-mail: nanotam@yandex.ru 
and portable electronic devices to electric power trains, hybrid buses, trucks, and cars-needs to collect and supply the required energy. One solution to these challenges is the use of a relatively new class of devices called supercapacitors.

The capacity of modern supercapacitors reaches thousands of Farads. The accumulation of energy in supercapacitor occurs in the process of charging due to the polarization of electric double layer at the anode-electrolyte and cathodeelectrolyte interfaces. In the liquid electrolyte, electric double layer has a thickness of up to nearly $1 \mathrm{~nm}$ that can be attributed to the principle of operation of the supercapacitors in the area of nano-electrochemistry. Supercapacitors should have a large area distributed in the volume of the device of the porous electrodes. Porous substances such as activated carbon or foam, with a specific surface area up to $1000-3000 \mathrm{~m}^{2} / \mathrm{g}$ are used as electrode materials in supercapacitors.

Modern supercapacitors generally have relatively low values of specific energy, so their use is limited and cannot fully meet the requirements of the market. To meet wide market needs, it is necessary to increase the specific energy up to 20-30 W-h/l, which is $2-4$ times higher than existing values $(5-10 \mathrm{~W}-\mathrm{h} / \mathrm{l})$. One of the main approaches to solving this problem is to increase the specific capacitance of the electrodes and increase the operating voltage.

A significant increase in operational characteristics of supercapacitors and hybrid power sources is possible through the using of new nanostructured materials, primarily of graphene materials (particularly, graphene nanoplatelets - GNPs), carbon nanotubes, and combinations thereof, and nanocomposite materials in which conductive carbon nanomaterial is a carrier for nano-sized particles or layers of electrochemically active components possessing highly developed surface and porosity, the electrically conductive polymers, compounds of transition metals, metalloids.

The most promising materials for the creation of conductive nanocomposites can be graphene nanoplatelets (GNPs), since the special methods of their processing allow to develop their specific surface area to $2500-3000 \mathrm{~m}^{2} / \mathrm{g}$ with retaining high electrical conductivity. Porous structure and surface area of these materials can be adjusted through the methods of processing (activation) of the GNPs themselves and through the creation of nanocomposites with other nano-sized particles or layers.

In the present work, the development of production technology of graphene nanoplatelets and their modified forms for use as electrodes of supercapacitors is described.

\section{Method of Obtaining GNPs}

A prototype of the method of obtaining the GNPs is described in [1-3]. According to this method, graphene nanoplatelets were received by exfoliation of expanded graphite materials, which were obtained by intercalation of the crystalline (natural) graphite GSM-1 with peroxo-sulfate compounds. Water or aqueous solutions of surfactants were used as a liquid medium for exfoliation. Ultrasonic treatment was used as a physical treatment method for exfoliation. 
Using graphene nanoplatelets in their original form (obtained after exfoliation) as electrode materials of supercapacitors is problematic due to the fact that they do not provide the required characteristics of porosity and specific surface area. For using electrode materials as energy storage devices, the materials should possess developed surface, porosity, and high electrical conductivity. The resolving of these problems was found by creating nanocomposite materials in which graphene nanoplatelets are electrically conductive and structure-forming component, while the layer of nanoporous (preferably mesoporous) carbon on the surface of the GNPs provides the necessary characteristics of specific surface area and porosity. To obtain such nanocomposites, organic precursors of the nanoporous (mesoporous) carbon were combined with GNPs and/or carbon nanotubes and then the composition was activated to achieve the desired nanocomposite structure.

\section{The Synthesis of the Nanocomposite GNPs/ (Nano-, Meso-Porous Carbon)}

As a precursor of nanoporous or mesoporous carbon water-soluble phenol-formaldehyde resin (PFR) was used in combination with components regulating the porous structure. Water-soluble carbohydrates or their derivatives (sugar, dextrin, carboxymethylcellulose were used as regulators of the porous structure. The aqueous solution of a carbohydrate was mixed with the PFR, and then mixed with the aqueous dispersion of graphene nanoplatelets, carbon nanotubes, or combination of them. Then the PFR was cured and preliminary carbonization of the mixture at a temperature of up to $300{ }^{\circ} \mathrm{C}$ was conducted.

The next stage was the chemical activation of the pre-carbonized material in molten potassium hydroxide at temperature up to $750{ }^{\circ} \mathrm{C}$. Then, the activated material was washed with water and treated with hydrochloric acid to remove iron impurities which arise from the walls of the steel reactor. Then the product was washed with water again, dried first in air at $110{ }^{\circ} \mathrm{C}$, and then in flow of argon at $350{ }^{\circ} \mathrm{C}$ to remove adsorbed water. Finally material with high surface area and porosity, with good electrochemical characteristics, containing 15-20 wt\% GNPs was obtained.

Taking into account the known literature data about the synergy of graphene nanoplatelets and carbon nanotubes in various applications, we have also synthesized hybrid materials containing graphene nanoplatelets, carbon nanotubes, and mesoporous carbon. The total content of nanocarbon components (GNPs + CNTs) in these materials amounted to $15-30 \%$. The introduction of nanocarbon components improved the porous structure of the material in terms of the transport pores, accelerating the penetration of ions in solution to the surface of the mesopores which mainly creates the electric double layer.

The parameters of the surface and porosity of the synthesized materials were determined with using the device Autosorb-IQ-MP (Quantachrom) by nitrogen 
adsorption at $77 \mathrm{~K}$. Specific surface area was determined by using multipoint BET method and the DFT method (calculation programs were integrated into the software of the device). Specific pore volumes and distribution of pores by width were determined using DFT method, assuming that the pores are slit like.

In Table 1 the parameters of the surface and porosity for several synthesized nanocomposite materials are compared. For comparison, the same data for the commercially available carbon materials for supercapacitors are presented (determined with using the same apparatus and calculation methods).

It should be noted that theoretically physical surface area for carbon materials cannot exceed the value of $2630 \mathrm{~m}^{2} / \mathrm{g}$ (monolayer of graphene). However, in literature BET surface areas of activated carbon materials up to $3000-4000 \mathrm{~m}^{2} / \mathrm{g}$ are often reported. This contradiction arises from the fact that the BET model is not adequate for such materials. However, it is used because it is the standard model for calculating surface area.

In Figs. 1 and 2, SEM images of the nanocomposite materials mesopores carbon/carbon nanotubes and mesopores carbon/graphene nanoplatelets are presented.

We can see from the images that the texture of the materials greatly depends on the nature of the nano-carbon component (nanotubes or graphene). One can assume that the lamellar structure of the material formed by graphene nanoplatelets will provide better diffusion of electrolyte ions in the volume of the electrode and thus provide the best power characteristics.

Table 1 Characteristics of porosity and specific surface area of carbon materials

\begin{tabular}{|c|c|c|c|}
\hline Carbon material & $\begin{array}{l}\text { Specific surface area } \\
(\text { Multipoint BET) } \\
\left(\mathrm{m}^{2} / \mathrm{g}\right)\end{array}$ & $\begin{array}{l}\text { The specific pore } \\
\text { volume } \\
\text { (DFT) }\left(\mathrm{cm}^{3} / \mathrm{g}\right)\end{array}$ & $\begin{array}{l}\text { The average pore } \\
\text { width } \\
\text { (DFT) }(\mathrm{nm})\end{array}$ \\
\hline \multicolumn{4}{|c|}{ Materials available on the market } \\
\hline Energ2 P2 & 1884 & 1.544 & 1.178 \\
\hline Energ2 V2 & 1217 & 0.601 & 0.899 \\
\hline XHAC & 1865 & 0.916 & 1.178 \\
\hline Kuraray YP-50F & 1356 & 0.700 & 0.899 \\
\hline Kuraray YP-80F & 2058 & 1.043 & 1.126 \\
\hline Norit DLC Supra30 & 1856 & 0.943 & 0.899 \\
\hline \multicolumn{4}{|c|}{ Materials synthesized by our technology (laboratory labels of samples are given) } \\
\hline $\begin{array}{l}\text { G_157-mesoporous } \\
\text { carbon/carbon } \\
\text { nanotubes }\end{array}$ & 3616 & 2.611 & 3.627 \\
\hline $\begin{array}{l}\text { S_048-mesoporous } \\
\text { carbon/graphene }\end{array}$ & 3202 & 2.496 & 3.627 \\
\hline $\begin{array}{l}\text { S_014-mesoporous } \\
\text { carbon }\end{array}$ & 2479 & 2.486 & 4.543 \\
\hline $\begin{array}{l}\text { S_020-mesoporous } \\
\text { carbon }\end{array}$ & 2517 & 3.069 & 4.152 \\
\hline
\end{tabular}



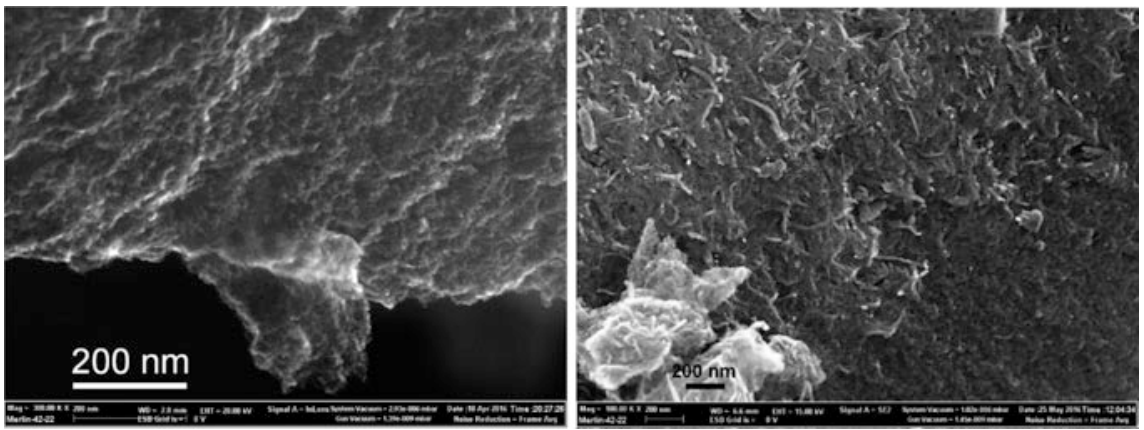

Fig. 1 SEM image of the nanocomposite material mesopores carbon/carbon nanotubes


Fig. 2 SEM image of the nanocomposite material mesopores carbon/graphene nanoplatelets

\section{Production and Testing of Electrode Materials}

The electrochemical characteristics of nanocomposite materials obtained were investigated together with "RICON" Ltd. (Voronezh, Russia). For manufacturing supercapacitor electrodes, the investigated carbon materials weighing $0.5 \mathrm{~g}$ were mixed with $0.05 \mathrm{~g}$ of the conductive filler (carbon SN-210), $1 \mathrm{ml}$ PTFE suspension F-4D (40 ml of isopropyl alcohol, $60 \mathrm{ml}$ of distilled water, $4.6 \mathrm{~g}$ of F-4D), $10 \mathrm{ml}$ of isopropyl alcohol was added to the mixture, and the mixture was treated $5 \mathrm{~min}$ by ultrasonic apparatus USG-15-0.1/22.

Then, the mixture was dried to remove the solvents from the obtained carbon mass containing the tested nanocomposite material. The electrodes were formed by pressing the carbon mass obtained with a force of 3 tons on a metal mesh made of stainless steel and having a cell size of $0.5 \mathrm{~mm}$. Before the experiment, the metal mesh was etched in the mixture of acids $\mathrm{HF}, \mathrm{HNO}_{3}, \mathrm{H}_{2} \mathrm{SO}_{4}(1: 1: 1)$, repeatedly washed with distilled water and isopropyl alcohol. Before the electrochemical measurements, the electrode was dried at $120{ }^{\circ} \mathrm{C}$ for $24 \mathrm{~h}$ to remove traces of adsorbed water. 
$3 \mathrm{M}$ aqueous sulfuric acid and $1 \mathrm{M}$ solution of tetraethylammonium tetrafluoroborate in acetonitrile (water content $<10 \mathrm{ppm}$ ) were used as electrolytes. For effectively filling the pores of the electrode material by the electrolyte solution vacuum impregnation was used. The electrochemical testing was performed in a standard three-electrode cell. To test the materials in aqueous electrolyte platinum wire was used as an auxiliary electrode and silver chloride electrode was used as a reference electrode. For testing the samples in nonaqueous electrolyte a platinum wire was used as an auxiliary electrode and Ag/Ag+ electrode RE-7 (ALS Co., Ltd, Japan) as a reference electrode. Cyclic voltammetric plots were obtained with using Elins P-30 J potentiostat. The researching electrochemical impedance is impedancemetry Elins Z-500P. Various current measurements were performed in the frequency range from $105 \mathrm{~Hz}$ to $1.4 \times 10^{-2} \mathrm{~Hz}$ with an amplitude of $10 \mathrm{mV}$.

Figure 3 shows the cyclic voltammetry curves with different scan speed potentials $(5-100 \mathrm{mV} / \mathrm{s})$ obtained in the sulfuric acid solution, and Fig. 4-cyclic voltammperometry in $1 \mathrm{M}$ TEABF4 solution in acetonitrile (AN).

On the basis of results of CVA curves, we found specific capacitance by the formula:

$$
C_{y \partial}=\frac{1}{m v\left(E_{\mathcal{K}}-E_{\mathcal{H}}\right)} \int_{E_{\mathcal{H}}}^{E_{\mathcal{K}}} I(E) \mathrm{d} E
$$

by integration method in Origin 8 Pro program.

The calculated data are shown in Table 2.

The obtained results prove that these nanocomposite materials are promising materials for use as electrode materials in supercapacitors. It should be noted also that with increasing the potential sweep speed, there is a significant fall in capacity,



Fig. 3 Cyclic voltammperometry in $3 \mathrm{M} \mathrm{H}_{2} \mathrm{SO}_{4}$ 


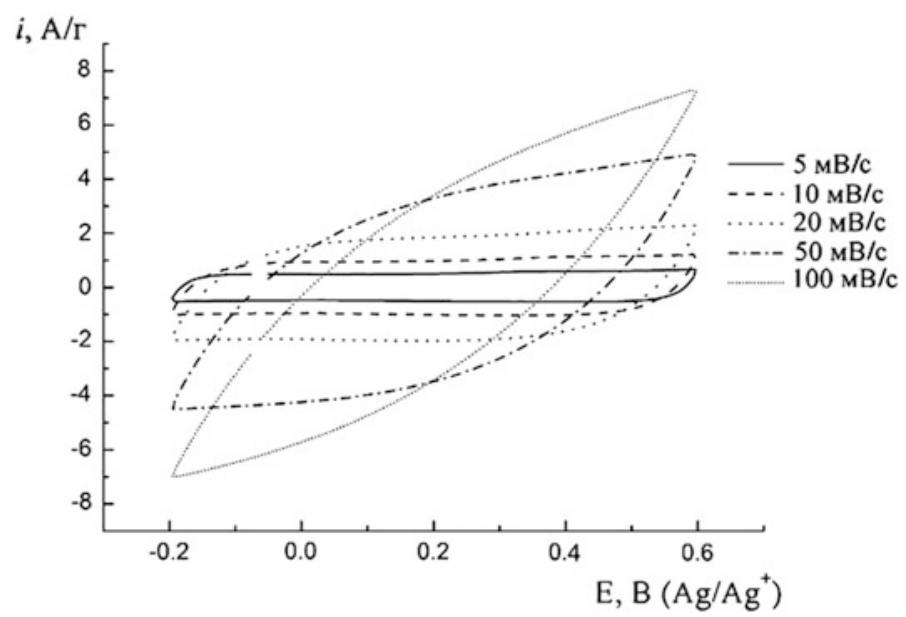

Fig. 4 Cyclic voltammperometry in $1 \mathrm{M}$ TEABF4 AN solution

Table 2 Specific capacitance of the investigated material in different electrolytes

\begin{tabular}{l|l|l|l|l|l}
\hline \multirow{2}{*}{ Electrolyte } & \multicolumn{5}{|l}{ Specific capacity C, F/g at the potential sweep rate $v, \mathrm{mV} / \mathrm{c}$} \\
\cline { 2 - 6 } & 5 & 10 & 20 & 50 & 100 \\
\hline $3 \mathrm{M} \mathrm{H}_{2} \mathrm{SO}_{4} /$ water & $161 \pm 8$ & $149 \pm 7$ & $137 \pm 7$ & $116 \pm 8$ & $97 \pm 8$ \\
\hline $1 \mathrm{M} \mathrm{TEABF}_{4} / \mathrm{AN}$ & $96 \pm 3$ & $89 \pm 4$ & $78 \pm 6$ & $50 \pm 9$ & $25 \pm 7$ \\
\hline
\end{tabular}

because of lack of transport pores in the material. For full usage of highly developed surface of synthesized materials at high sweep speed (high frequency) it is necessary to modify the texture of these materials so as to create large transport pores, which can be achieved by choosing the optimal concentration of additives of nanocarbon components.

\section{Manufacturing and Testing Supercapacitors Based on Developed Materials}

For testing the supercapacitors of various of sizes with a diameter of 11 and $15 \mathrm{~mm}$, height 23 and $34 \mathrm{~mm}$ were manufactured. We added the soot Vulcan to the developed carbon material for manufacturing electrodes of supercapacitors. The addition of the soot in the composite mixture reduces its specific capacity, but improves its mechanical and technological properties. Manufacturing of electrode material on the basis of only the materials developed and further work with him is almost impossible due to the lack of mechanical strength. 
For fabricated experimental samples of supercapacitors it was measured as the internal resistance ESRAC alternating current frequency of $1 \mathrm{kHz}$, and recorded the number of included electrodes (anodes, cathodes) of the carbon material. The results for the calculation of specific power and energy density and their values are given in Tables 3 and 4, respectively.

Table 3 Experimental data and calculated specific power

\begin{tabular}{|c|c|c|c|}
\hline \multicolumn{3}{|c|}{ Characteristics of experimental samples } & \multirow{2}{*}{$\begin{array}{l}\text { Specific power } P \\
(\mathrm{KW} / \mathrm{kg})\end{array}$} \\
\hline Limit voltage $U_{\mathrm{H}}, \mathrm{v}$ & $\mathrm{ESR}_{\mathrm{AC}}, \mathrm{OM}_{\mathrm{M}}$ & Weight $M(\mathrm{~kg})$ & \\
\hline \multirow[t]{13}{*}{2.7} & \multirow[t]{2}{*}{0.015} & 0.00387 & 31.4 \\
\hline & & 0.00397 & 30.6 \\
\hline & \multirow[t]{2}{*}{0.010} & 0.00600 & 30.2 \\
\hline & & 0.00600 & 30.1 \\
\hline & \multirow[t]{2}{*}{0.0060} & 0.00990 & 30.7 \\
\hline & & 0.00980 & 31.0 \\
\hline & \multirow[t]{2}{*}{0.014} & 0.00372 & 35.0 \\
\hline & & 0.00379 & 34.3 \\
\hline & \multirow[t]{2}{*}{0.010} & 0.00610 & 29.9 \\
\hline & & 0.00600 & 30.4 \\
\hline & \multirow[t]{2}{*}{0.0065} & 0.00868 & 32.3 \\
\hline & & 0.00884 & 31.7 \\
\hline & 0.0055 & 0.00884 & 37.5 \\
\hline
\end{tabular}

Table 4 Experimental data and calculated specific energy

\begin{tabular}{|c|c|c|c|}
\hline \multicolumn{3}{|c|}{ Characteristics of experimental samples } & \multirow{2}{*}{$\begin{array}{l}\text { Calculated values of } \\
\text { specific energy, } E \text { (wt h/kg) }\end{array}$} \\
\hline $\begin{array}{l}\text { Limit } \\
\text { voltage } \\
U_{\lim }(\mathrm{v})\end{array}$ & $\begin{array}{l}\text { Capacity } \\
C(\mathrm{~F})\end{array}$ & $\begin{array}{l}\text { The mass of carbon in the } \\
\text { electrode of the sample } m(\mathrm{~kg})\end{array}$ & \\
\hline \multirow[t]{12}{*}{2.7} & 7.3 & 0.000271 & 26.9 \\
\hline & 7.6 & 0.000285 & 26.7 \\
\hline & 14.6 & 0.000533 & 27.4 \\
\hline & 13.0 & 0.000520 & 25.0 \\
\hline & 25.5 & 0.000934 & 27.3 \\
\hline & 25.9 & 0.000952 & 27.2 \\
\hline & 7.9 & 0.000317 & 24.9 \\
\hline & 8.1 & 0.000324 & 25.0 \\
\hline & 16.3 & 0.000644 & 25.3 \\
\hline & 15.0 & 0.000595 & 25.2 \\
\hline & 24.5 & 0.000953 & 25.7 \\
\hline & 25.4 & 0.000966 & 26.3 \\
\hline
\end{tabular}


The specific energy of the test subject, referred to the weight of carbon in sample was calculated by the formula

$$
E_{\mathrm{yd} .}=\frac{C \cdot U^{2}}{2 \cdot 3600 \cdot m} \mathrm{Wh} / \mathrm{kg},
$$

C Capacitance of the sample $f$

$\mathrm{U}$ Limit voltage $\mathrm{v}$

M Weight of carbon in the sample $\mathrm{kg}$

The specific capacity of the tested objects was calculated by the formula

$$
P_{\mathrm{yz} .}=\frac{U^{2}}{4 \cdot E S R_{A C} \cdot M} \mathrm{KW} / \mathrm{kg} \text {, }
$$

$U \quad$ Limit voltage $\mathrm{w}$;

$\mathrm{ESR}_{\mathrm{AC}}$ the internal resistance of the alternating current, OM;

$M \quad$ the mass of sample, $\mathrm{kg}$.

\section{Conclusions}

The technology of producing graphene nanoplatelets based on the method of intercalation of crystalline graphite and subsequent ultrasonic exfoliation in aqueous medium was developed.

The technology of production of nanocomposites GNPs/(nano-, meso-porous carbon) for use as electrodes in supercapacitors was developed. It is established that the introduction of GNPs in the composition of the nanoporous (mesoporous) carbon changes its structure with formation of large-pore plate-like texture, which apparently provides better diffusion of electrolyte ions in the volume of the electrode.

Electrochemical studies of the developed composite materials in aqueous and nonaqueous electrolytes were conducted and cyclic voltammetric curves were obtained, which allow calculating the specific capacitance of the carbon nanocomposites.

It was made samples of supercapacitors based on the developed materials, identified by their operating characteristics: power density of supercapacitors experimental samples was more than $30 \mathrm{~kW} / \mathrm{kg}$ (in terms of carbon material), the specific energy more than $25 \mathrm{~W} \mathrm{~h} / \mathrm{kg}$.

Acknowledgements The research was conducted with the financial support represented by the Ministry of Education and Science of the Russian Federation. Agreement no. 14.577.21.0091 22 Jul. 2014. Unique project Identifier: RFMEFI57714X0091. 


\section{References}

1. Melezhyk, A.V., Tkachev, A.G.: Synthesis of graphene nanoplatelets from peroxosulfate graphite intercalation compounds. Nanosyst.: Phys. Chem. Math. 5(2), 294-306 (2014)

2. Melezhyk, A.V., Kotov, V.A., Tkachev, A.G.: Optical properties and aggregation of graphene nanoplatelets. J. Nanosci. Nanotechnol. 16(1), 1067-1075 (2016)

3. Melezhik, A.V., Pershin, V.F., Memetov, N.R., Tkachev, A.G.: Mechanochemical synthesis of graphene nanoplatelets from expanded graphite compound. Nanotechnol. Russ. 11(7-8), 421429 (2016). (C) Pleiades Publishing, Ltd., 2016. - Original Russian Text (C) Melezhik, A.V., Pershin, V.F., Memetov, N.R., Tkachev, A.G., 2016, published in Rossiiskie Nanotekhnologii 11, 7-8 (2016)

Open Access This chapter is licensed under the terms of the Creative Commons Attribution 4.0 International License (http://creativecommons.org/licenses/by/4.0/), which permits use, sharing, adaptation, distribution and reproduction in any medium or format, as long as you give appropriate credit to the original author(s) and the source, provide a link to the Creative Commons license and indicate if changes were made.

The images or other third party material in this chapter are included in the chapter's Creative Commons license, unless indicated otherwise in a credit line to the material. If material is not included in the chapter's Creative Commons license and your intended use is not permitted by statutory regulation or exceeds the permitted use, you will need to obtain permission directly from the copyright holder.

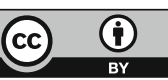

